\title{
Effect of blood transfusion on central venous oxygen saturation in anemic patients on intensive care unit
}

\author{
Abd-Elsalm WM'1 ${ }^{1}$ Elbradie GF ${ }^{2}$, El-Shehdawy $\mathrm{SR}^{2}$ and Soliman $\mathrm{SM}^{2}$ \\ ${ }^{1}$ Department of anesthesia and surgical intensive care, Kafr Elsheikh University faculty of Medicine, Egypt \\ ${ }^{2}$ Department of anesthesia and surgical intensive care, Tanta University faculty of Medicine, Egypt
}

\begin{abstract}
Introduction: Anemia is a major problem in Intensive care units (ICU). Many patients are exposed to anemia during their stay in ICU. Many factors contribute to anemia such as repeated phelipotmies, associated chronic health problems, the devastating disease that admits the patient to ICU, sepsis. The aim of this study is to evaluate the effect of blood transfusion on $\mathrm{SVO}_{2}$ in anemic patients in intensive care units and the possibility of using it as a guide for blood transfusion in ICU.

Methods: This study was carried out in Tanta University Hospitals in surgical intensive care unit for one year on critically ill intensive care unit (ICU) patients with anemia $(\mathrm{Hb}<7 \mathrm{~g} / \mathrm{dl})$. Forty patients were included in the study. Patients were divided retrospective into two groups according to central venous oxygen saturation $\left(\mathrm{ScvO}_{2}\right)$ before blood transfusion; Group $\mathrm{A}: \mathrm{ScvO}_{2}$ equal or more than $70 \%$.and Group B: ScvO2 less than $70 \%$. Then 15 min after completion of the transfusion, similar sample was taken, and the blood gas analysis was repeated.
\end{abstract}

Results: As regard hemoglobin and hematocrit value, blood transfusion provided a significant and approximately similar increase for all patients in both groups. There was no significant difference as regard heart rate, central venous pressure, $\mathrm{MAP}, \mathrm{SaO}_{2}$ and lactate in the two groups before and after blood transfusion.

Conclusions: Central venous oxygen saturation can be used as adjuvant clinical tool for blood transfusion.

\section{Introduction}

Anemia is a major problem in Intensive care units (ICU). Many patients are exposed to anemia during their stay in ICU. Many factors contribute to anemia such as repeated phelipotmies, associated chronic health problems, the devastating disease that admits the patient to ICU, sepsis $[1,2]$.

Blood transfusion is used with commonly in ICU to treat anemia. And it is associated with lethal side effects such as transmission of blood born infection like HIV and HCV. Transfusion overload, Transfusion related acute lung injury and Anaphylactic shock $[3,4]$.

The decision to transfuse blood should not base solely on hemoglobin level. It should also integrate other factors such as the clinical condition of the patient and central venous oxygen saturation [5].

Central venous oxygen saturation is considered as a clinical tool for whole body oxygen uptake-delivery relationship. It is difficult and carries a lot of complications, to insert pulmonary artery catheter to measure mixed venous oxygen saturation $\left(\mathrm{SvO}_{2}\right)$, the central venous oxygen saturation $\left(\mathrm{ScvO}_{2}\right)$ is increasingly being used as a reasonably accurate surrogate [6].

Central venous catheters (CVCs) are simpler to insert, and generally safer and cheaper than PACs. The CVC allows sampling of blood for measurement of $\mathrm{ScvO}_{2}$. The normal range for $\mathrm{SvO}_{2}$ is 68 to $77 \%$ and $\mathrm{ScvO}_{2}$ is $5 \%$ above these values $[7,8]$.

Oxygen extraction ratio is increased as compensatory mechanism during anemia. In normal people, oxygen extraction is normally not exceeding $25 \%$. The $\mathrm{O}_{2}$ extraction ratio (ER), which is the ratio of whole- body $\mathrm{O}_{2}$ consumption to $\mathrm{O}_{2}$ delivery, approaches 50 percent when the limits of compensation are reached. Oxygen extraction is recently used as adjuvant factor in blood transfusion decision. central venous oxygen saturation is considered to be alternative for Oxygen extraction ratio as a guide for blood transfusion [6,9].

The aim of this study is to evaluate the effect of blood transfusion on $\mathrm{SVO}_{2}$ in anemic patients in intensive care units. And the possibility of using it as a guide for blood transfusion in ICU.

\section{Patients and methods}

This study was carried out in Tanta University Hospitals in surgical intensive care unit for one year on critically ill intensive care unit (ICU) patients with anemia $(\mathrm{Hb}<7 \mathrm{~g} / \mathrm{dl})$. Forty patients were included in the study

\section{Study setting and population}

We include all adult Patients aged above 18 years, Patients with $\mathrm{Hb}<7 \mathrm{~g} / \mathrm{dl}$, Mean arterial blood pressure (MAP) $\geq 65 \mathrm{~mm} \mathrm{Hg}$. and their urine output $\geq 0.5 \mathrm{ml} / \mathrm{kg} / \mathrm{hr}$. we exclude all patients with increased oxygen consumption (shivering, epilepsy, pain), Ongoing

${ }^{\star}$ Correspondence to: Wafaa M Abd-Elsalam, Department of anesthesia and surgical intensive care, Kafr Elsheikh University faculty of Medicine, Egypt, Tel: 00201060909040; E-mail: tantamedicalresearch@yahoo.com

Key words: blood transfusion, anemia, central oxygen saturation

Received: November 30, 2018; Accepted: December 12, 2018; Published: December 17, 2018 
hemorrhage, Shock of any origin and any patient on vasopressor support, Chronic anemia, Hypoxemia, and Patients with ischemic heart disease, acute coronary syndrome or heart failure.

\section{Study protocol}

This study was carried out on anemic patients (hemoglobin $<7 \mathrm{~g} /$ dl) who need blood transfusion according to French recommendation of blood transfusion using threshold values for hemoglobin together with the clinical context to indicate blood transfusion. Central venous blood samples were taken and a blood gas analysis immediately before blood transfusion was undertaken. Patients were divided retrospective into two groups according to central venous oxygen saturation $\left(\mathrm{ScvO}_{2}\right)$ before blood transfusion; Group $\mathrm{A}: \mathrm{ScvO}_{2}$ equal or more than $70 \%$ and Group B: $\mathrm{ScvO}_{2}$ less than $70 \%$. Then 15 min after completion of the transfusion, similar sample was taken, and the blood gas analysis was repeated. Then we compared central venous oxygen saturation before and after transfusion. If a patient received more than 1 unit of packed cells, central venous oxygen saturation will be recorded before the first unit and $15 \mathrm{~min}$ after completion of the last unit. The following measurements were recorded before and $15 \mathrm{~min}$ after transfusion:1Hemoglobin level (mg/dl).2- Haematocrite level (\%).3-Central venous pressure $\left(\mathrm{cmH}_{2} \mathrm{O}\right) .4$ - Heart rate $(\mathrm{b} / \mathrm{min})$. 5-Mean arterial blood pressure (mmHg). 6-SaO 2 (arterial oxygen saturation) (\%). 7-Serum lactate $(\mathrm{mmol} / \mathrm{L})$.

\section{Results}

In this study the mean of the age in group A was $43.330 \pm 13.089$ $y$ and it was similar in the other group with mean of $46.390 \pm 10.300$ $\mathrm{y}$. The males were more predominant in the two groups with $58.3 \%$ in group A and $60.7 \%$ in group B.
As regard hemoglobin and hematocrit value, blood transfusion provided a significant and approximately similar increase for all patients in both groups (Table 1).

There was no significant difference as regard heart rate, central venous pressure, MAP, $\mathrm{SaO} 2$ and lactate in the two groups before and after blood transfusion.

In group $\mathrm{B}$ there was significant increase in $\mathrm{ScvO}_{2}$ and significant decrease in $\mathrm{O} 2$ extraction after blood transfusion while there was no significant difference in both in group A.

\section{Discussion}

Blood transfusion is a common practice in Intensive Care Units. In this study, blood transfusion lead to significant increase in $\mathrm{ScVO}_{2}$ when it was $<70 \%$ before transfusion.

In agreement with our study Mungayi et al. [10] who found that there was no significant increase in $\mathrm{ScvO}_{2}$ after blood transfusion in patients with Oxygen extraction less than $30 \%$ i.e. $\mathrm{ScvO}_{2} \geq 70 \%$ and majority of patients (60.3\%) who were transfused did not physiologically require $\mathrm{RBC}$ transfusion and did not benefit from increased oxygen content.

Also, in agreement with our study, Adamczyk et al. enrolled 60 hemodynamically stable patients in their study. $\mathrm{ScvO}_{2}(\%)$ and hemoglobin $(\mathrm{g} / \mathrm{dl})$ were measured before and after blood transfusion. Patients were retrospectively divided into two groups according to $\mathrm{ScvO}_{2}$ measured before blood transfusion (<or $\left.>70 \%\right)$. Following blood transfusion, the $\mathrm{ScvO}_{2}$ increased significantly (from 57.8 to $68.5 \%$ ) in the group with initial $\mathrm{ScvO}_{2}$ less than $70 \%$ whereas it was unchanged in patients with initial $\mathrm{ScvO}_{2}$ greater or equal $70 \%$ (from 76.8 to $76.5 \%$ ).

Table 1. $\mathrm{ScVO} 2=\mathrm{Central}$ venous oxygen saturation. $\mathrm{Hg}=$ hemoglobin. $\mathrm{Htc}=$ hematocrit. $\mathrm{CVP}=$ central venous pressure. $\mathrm{SaO} 2=\mathrm{Arterial}$ oxygen saturation $\mathrm{MAP}=$ mean arterial pressure

\begin{tabular}{|c|c|c|}
\hline & Group A & Group B \\
\hline Age Mean \pm Sd & $43.33 \pm 13.089$ & $46.39 \pm 10.3$ \\
\hline \multicolumn{3}{|l|}{ Sex } \\
\hline Male & $58.30 \%$ & $60.70 \%$ \\
\hline Female & $41.30 \%$ & $39.30 \%$ \\
\hline $\mathrm{ScVO}_{2}$ BEFORE TRANSFUSION Mean $\pm \mathrm{SD}$ & $79.958 \pm 2.472$ & $59.946 \pm 3.598$ \\
\hline $\mathrm{ScVO}_{2}$ AFTER TRANSFUSION Mean $\pm \mathrm{SD}$ & $81.458 \pm 1.096$ & $74.017 \pm 2.565$ \\
\hline P Value & 0.106 & $0.0000 *$ \\
\hline $\mathrm{Hb}$ Before Transfusion Mean $\pm \mathrm{Sd}$ & $6.158 \pm 0.308$ & $5.939 \pm 0.508$ \\
\hline $\mathrm{Hb}$ After Transfusion $\mathrm{Mean} \pm \mathrm{Sd}$ & $7.442 \pm 0.276$ & $7.507 \pm 0.338$ \\
\hline P Value & $0.000 *$ & $0.0000 *$ \\
\hline Htc Before Transfusion & $19.083 \pm 0.9$ & $18.607 \pm 1.03$ \\
\hline Htc After Transfusion Mean $\pm \mathrm{Sd}$ & $24.75 \pm 0.866$ & $23.928 \pm 0.94$ \\
\hline P Value & $0.000 *$ & $0.000^{*}$ \\
\hline CVP Before Transfusion Mean $\pm \mathrm{Sd}$ & $8.666 \pm 1.45$ & $8.071 \pm 1.412$ \\
\hline CVP After Transfusion Mean $\pm \mathrm{Sd}$ & $9.166 \pm 1.527$ & $8.321 \pm 0.818$ \\
\hline P Value & 0.4 & 0.282 \\
\hline HR Before Transfusion Mean $\pm \mathrm{Sd}$ & $79.5 \pm 11.508$ & $81.892 \pm 8.642$ \\
\hline HR After Transfusion Mean \pm Sd & $78.832 \pm 9.058$ & $80.035 \pm 8.324$ \\
\hline P Value & 0.176 & 0.372 \\
\hline MAP Before Transfusion Mean \pm Sd & $79.500 \pm 11.508$ & $74.570 \pm 7.461$ \\
\hline MAP After Transfusion Mean $\pm \mathrm{Sd}$ & $78.832 \pm 9.059$ & $75.000 \pm 6.543$ \\
\hline P Value & 0.176 & 0.554 \\
\hline $\mathrm{SaO}_{2}$ Before Transfusion Mean $\pm \mathrm{Sd}$ & $98.416 \pm 1.083$ & $97.357 \pm 1.311$ \\
\hline $\mathrm{SaO}_{2}$ After Transfusion Mean $\pm \mathrm{Sd}$ & $98.583 \pm 0.792$ & $97.535 \pm 1.137$ \\
\hline P Value & 0.504 & 0.605 \\
\hline Lactate Before Transfusion Mean $\pm \mathrm{Sd}$ & $0.783 \pm 0.216$ & $0.907 \pm 0.307$ \\
\hline Lactate After Transfusion Mean $\pm \mathrm{Sd}$ & $0.817 \pm 0.019$ & $0.817 \pm 0.311$ \\
\hline P Value & 0.586 & 0.057 \\
\hline
\end{tabular}


They recommend that $\mathrm{ScvO}_{2}$ could be a relevant biological parameter to complete the current guidelines for blood transfusion in stable patient with a central venous catheter during the postoperative period [9].

In agreement with our study, Orlov et al. [11] proved that $\mathrm{O}_{2}$ extraction does not significantly change after blood transfusion if the base line was normal. Also, they found that many RBC transfusions in anemic patients took place in the setting of a normal O2ER, and temporal differences in O2ER after RBC transfusions were found to vary as a function of pre-transfusion O2ER. Specifically, more than 40 percent of RBC transfusions given solely for low $\mathrm{Hb}$ concentration were in patients whose pre-transfusion O2ER was normal and posttransfusion O2ER decreased in patients with elevated pre-transfusion O2ER.

In agreement with our study, Sehgal et al. [12] demonstrated that using $\mathrm{O} 2$ Extraction as a transfusion trigger could potentially reduce the number of blood transfusion. They showed that if they had used $\mathrm{O} 2$ Extraction of 0.50 as a transfusion trigger, then only 7 out of 41 patients in the transfusion group would have been transfused. Also suggest that using $\mathrm{O} 2$ extraction along with some other clinical risk factors as preoperative ejection fraction, age ,body surface area and recent clinical history as a part of transfusion algorithm and with conjugation with blood conservative measures can reduce blood transfusion.

Adamczyk et al. [9] and Rivers et al. [13] concluded that $\mathrm{ScvO}_{2}$ could be an important parameter guiding transfusion decisions in patients with severe sepsis or in stable high-risk patients equipped with $\mathrm{CVC}$, and that $\mathrm{ScvO}_{2}$ can be proposed as universal physiological transfusion trigger.

O'Farrell conducted a pilot study in 2006 that measured the relationship between O2ER and postoperative RBC transfusions in cardiac surgery and concluded that elevated O2ER may be a more appropriate transfusion trigger than low hemoglobin concentration and its use may reduce inappropriate transfusion [14].

On contrary to our study, in 2014 Fiser et al. [10] investigated the effect of RBC transfusion in 45 pediatric patients with ECMO and found that transfusion did not significantly alter global tissue oxygenation. In this study, most transfusions were given when the patient did not appear to be oxygen delivery dependent. Thus, Fiser et al. [10] recommended other studies to investigate the effects of blood transfusion in decreasing pretransfusion $\mathrm{O}_{2}$ extraction.

\section{Limitation of the study}

The study was single center study; also, the small number of patients due to exclusion criteria of the study.

\section{Conclusion}

Central venous oxygen saturation can be used as adjuvant clinical tool for blood transfusion.

\section{Authorship}

Sohair Soliman, Ghada Elbradie, Sameh Elshehdawy, Wafaa Abdelsalam were behind the idea of the research, collected the data of the patients and follow up the patients in the Intensive Care Unit. Sohair Mostafa Soliman did the statistics. Ghada Fouad Elbradie and Wafaa Abdelsalam wrote the manuscript. All authors revised the manuscript.

\section{Acknowledgments}

I would like to thank Dr. Mohamed G. Elbahnasawy and Dr Sherief Abd-Esalam for their kind support.

\section{Funding}

The author(s) received no financial support for the research, authorship, and/or publication of this article.

\section{Declaration of conflicting interests}

The author(s) declared no potential conflicts of interest with respect to the research, authorship, and/or publication of this article.

\section{Informed consent}

Written Informed consent was obtained from every patient or their relative participate in the study. The patient or his relative received an explanation on the purpose of the study and patient had a secret code number to ensure privacy to participants and confidentiality of the data.

The study protocol conforms to the ethical guidelines of the 1975 Declaration of Helsinki as reflected in a priori approval by the institution's human research committee.

\section{Ethical approval}

Ethical approval for the study was obtained from ethical committee of Tanta University Faculty of Medicine before the start of the research.

\section{Human rights}

The study protocol conforms to the ethical guidelines of the 1975. Declaration of Helsinki as reflected in a priori approval by the institution's human research committee.

\section{References}

1. Corwin HL, Gettinger A, Pearl RG, Fink MP, Levy MM, et al. (2004) The CRIT Study: anemia and blood transfusion in the critically ill - current clinical practice in the United States. Critical care medicine. 32:39-52.

2. Muraro A, Roberts G, Worm M, Bilò MB, Brockow K, et al. (2014) Anaphylaxis guidelines from the European Academy of Allergy and Clinical Immunology. Allergy 69: 1026-1045. [Crossref]

3. Benson AB, Moss M, Silliman CC (2009) Transfusion-related acute lung injury (TRALI): a clinical review with emphasis on the critically ill. Br J Haematol 147: 431-443. [Crossref]

4. Bolton-Maggs PH, Cohen H (2013) Serious Hazards of Transfusion (SHOT) haemovigilance and progress is improving transfusion safety. Br J Haematol 163: 303314. [Crossref]

5. Paone G, Silverman NA (1997) The paradox of on-bypass transfusion thresholds in blood conservation. Circulation 96(9 Suppl): II-205-8; discussion II-9.

6. Dueck MH1, Klimek M, Appenrodt S, Weigand C, Boerner U (2005) Trends but not individual values of central venous oxygen saturation agree with mixed venous oxygen saturation during varying hemodynamic conditions. Anesthesiology 103: 249-257. [Crossref]

7. Vallet B, Tavernier B, Lund N (2000) Assessment of tissue oxygenation in the criticallyill. Eur J Anaesthesiol 17: 221-229. [Crossref]

8. Vallet B, Robin E, Lebuffe G (2010) Venous oxygen saturation as a physiologic transfusion trigger. Critical care (London, England). 14:213.

9. Adamczyk S, Robin E, Barreau O, Fleyfel M, Tavernier B, et al. (2009) Contribution of central venous oxygen saturation in postoperative blood transfusion decision. Annales francaises d'anesthesie et de reanimation; 2009.

10. Mung'ayi V, Sharif T, Odaba DS (2014) Blood transfusion and oxygen extraction ratio in patients admitted to the general intensive care unit: A quasi experimental study. $A f r$ J Emerg Med 4: 66-70. 
11. Orlov D, O'Farrell R, McCluskey SA, Carroll J, Poonawala H, et al. (2009) The clinical utility of an index of global oxygenation for guiding red blood cell transfusion in cardiac surgery. Transfusion 49: 682-688. [Crossref]

12. Sehgal LR, Zebala LP, Takagi I, Curran RD, Votapka TV, et al. (2001) Evaluation of oxygen extraction ratio as a physiologic transfusion trigger in coronary artery bypass graft surgery patients. Transfusion 41: 591-595. [Crossref]
13. Rivers E, Nguyen B, Havstad S, Ressler J, Muzzin A, et al. (2001) Early goal-directed therapy in the treatment of severe sepsis and septic shock. $N$ Engl $J$ Med 345: 13681377. [Crossref]

14. O'Farrell R, Ghannam M, McCluskey M, Beattie S, Karkouti K (2006) Oxygen extraction ratio (OER) and blood transfusion in cardiac surgery. Can J Anaesth 53 : 26342.

Copyright: $\mathbb{C} 2018$ Abd-Elsalm WM. This is an open-access article distributed under the terms of the Creative Commons Attribution License, which permits unrestricted use, distribution, and reproduction in any medium, provided the original author and source are credited. 